\title{
Difficulties to Use (Twitter) in the Educational Process from the Perspective of Social Studies Teachers in the State of Kuwait
}

\author{
Saleh Abdulrahem Alsaeed \\ Ministry of Education, Kuwait
}

Copyright $\subseteq 2016$ by authors, all rights reserved. Authors agree that this article remains permanently open access under the terms of the Creative Commons Attribution License 4.0 International License

\begin{abstract}
This study aimed to know the difficulties of use Twitter in the educational process from the perspective of social studies teachers in the State of Kuwait, in order to achieve the objectives of the study researchers answered the following question: What are the difficulties faced when using (Twitter) in the educational process from the standpoint of social studies teachers in the State of Kuwait? In order To answer the study question the researcher Prepared and designed A questionnaire as the tools of study about the difficulties of use Twitter in the educational process from the perspective of social studies teachers, and the number of respondents (150) members. The results of the study revealed the existence of many of the difficulties experienced by teachers in the use of Twitter in the educational process.
\end{abstract}

Keywords Twitter, Difficulties, Social Studies, Teachers

\section{Introduction}

World Information Network has evolved from being just a means of disseminating information (web 1) to a means of communication and networking (Web 2), this has helped to move the learner from a non-reactive recipient to an effective learner and a participant in the services and applications. The learner has also moved from focusing on preset contents to interactive media produced by the learner cooperating with others through the use of second generation Web tools (Web 2) such as blogs, wikis, social favorites and social networks characterized by interaction and communication in a default cooperative environment. [1].

Social webs provide the possibility of communication between people with same interests or same certain disciplines to share files, photos, videos and send instant messages and talk together. Twitter is considered one of the most important social webs that have gained great fame the number of its users in the Arab world has reached about 101 million users. [2]

Because it allows participants to express their opinions with sound and pictures, share files, videos, and access to all participants worldwide. For teachers and learners, the web is a means of social interaction it saves the opportunity to create Web pages and put up topics and add comments on the web.

There is no doubt that information revolution, and the increasing techniques of education in our time form a challenge for educators and those in charge of the educational process in light of these developments. Educators and those in charge of the educational process need to take advantage of educational technologies to keep up with the information age. Modern technology may contribute to the development of methods and new ways of teaching to solve many of the problems faced by the education system as the goal of education is no longer just to give the student knowledge and facts, but its goal has extended to include providing the students with skills, abilities, and self-reliance to be able to interact with the changes of the age. In addition to the above-mentioned, some educators believe that Twitter and other social networks have helped to solve an educational problem represented in the lack of the humanitarian side in E-learning; they say that it is a "rigid education". Twitter and other social networks have added the human and social character to it through the participation and interaction of the human element with the educational process this has helped to attract learners and increase their desire to learn. [3]

So, educational institutions in the State of Kuwait should take advantage of the Twitter in creating social learning environments that enable them to keep up with developments and integrate technology with education, because as (Salameh)[4] pointed out that education in general and instruction in particular were not far from these developments. Educational institutions should continuously seek to benefit from these developments to break the gap between what the students learn in educational institutions 
and what they experience in their real life. Moreover, Twitter is a fertile field for teachers of social studies who can do many interesting and useful activities and techniques to support the teaching of the school subject and through the following: Examples of the use of Twitter in instruction and activities

1. A question to learners: Mention some of the useful books to read for students of first prep?

2. Preparing a list of useful books for teaching social studies.

3. Thanking some learners who tweeted on a particular topic.

4. Participating in some social events such as birthdays, honoring pioneer student.

5. Giving teachers some advice on how to integrate technology with education through web sites like www.ilearntechnology.com

6. Using Twitter in some useful web sources such as blogs, websites and books.

7. Making live chat to help learners to participate in the activities of the Open Day like for http://www.edweek.org.

8. Viewing a video shot on a subject and answering questions about it with learners.

\section{Ideas for Teaching Using Twitter}

1. as a schedule to inform learners about the subject content, dates and places of lectures as well as the methods of assessment and how to calculate the grades and evaluate the course objectives review and duties.

2. Asking the learners to read an article or a book chapter, and summarizing it or summarizing the main points of a certain lecture in about 140 characters and making this available to participate in.

3. Asking the learners to look for sites' links related to the topic of the syllabus and making it available to participate and then assembling and placing it on the professor page.

4. Teachers look for an important event or occasion suitable to be an introduction to the syllabus then learners are asked to pursue the syllabus, its shots, scenes and pictures.

5. Choose one of the persons that have contributed to the development of information, definitions or theories of one of the syllabus topics then ask a group of the learners to research and share on their Twitter pages.

6. Recognizing the scientific and social backgrounds of the learners and speak to them through the program and learn more about their cultures, hobbies and friends.

7. Encouraging a group of learners to ask as many of the questions related to the syllabus as possible and asking them to participate and discuss how they relate to the goals.

Terry and Friedman added that the use of Twitter in the educational process is not free from some of the following weaknesses:
1. Long discussions sometimes cause dispersal to some learners who suffer from autism, attention deficit disorder and chronic fatigue.

2. In-depth discussions may take a long time.

3. Discussions may be tough, from the point of view of some learners when there are no compliments.

4. Cause Internet addiction.

5. Help to spread rumors very quickly.

6. Excessive privacy and writing in the range of 140 characters.

7. Discussions may branch away from the selected topic.

There are important things that should be taken into account when using Twitter in the educational process:

1. Providing the learners with an introduction about how to use and to participate well in the program to take advantage of the time.

2. Exerting much effort to make students participate well and actively.

3. Try to be interested in the self-learning issue.

4. Flexibility in the assessment as much as possible.

5. Encouragement and urging learners to participate in it.

6. Experimenting the idea on a small group before circulating it to the rest of the learners.

7. Providing adequate time for students to accomplish their duties and providing them bigger opportunity. [5]

Hence, this study aims to shed light on how difficult it is to use the social networking programs (Twitter) in the educational process from the perspective of social studies teachers in the State of Kuwait.

\section{The Study Problem}

The study problem is determined in answering the following question: - What are the difficulties faced when using (Twitter) in the educational process from the standpoint of social studies teachers in the State of Kuwait?

\section{The Importance of the Study}

1. Detecting Twitter difficulties in the educational process and highlighting them in front of the education society.

2. Inform officials in the Ministry of Education about the advantages of Twitter programs in the educational process.

3. Recognizing the advantages of Twitter programs and making use of them in teaching and learning processes.

\section{Research Limits}

Time limits: the study was carried out in the second semester of 2014-2015- Spatial limits: The study was applied to a sample of social studies teachers in the General administration of educational in Jahra area. 


\section{Procedural Definitions}

\section{Social Networking (Twitter)}

Grosseck and Holotescu, [5]define it as a small blog, a Web Technology 2 and a new form of blogs, which allows users to publish brief text consisting usually of 140-200 characters online, as well as images and other files, it provides real-time interaction among users using various devices and technologies through Twitter.

\section{Previous Studies}

1. AlHazani (2013) made a study aiming to identify the effectiveness of social networks on the development of teaching and learning process to the students of the Faculty of Education at King Saud University, the study sample consisted of student girls in the Faculty of Education at King Saud University, departments of special education, Islamic Culture, curricula and teaching methodology, technical education, educational administration, psychology and kindergartens. Thirty three student girls were selected from each department and the results of the study showed clearly the effectiveness of using social networks in the development of teaching and learning process. [6]

2. AlAnzi (2013) conducted a study aiming to identify the effectiveness of the use of social networks in learning and measure attitudes towards the knowledge society at the third grade primary stage in Medina The study sample consisted of 63 student girls. The results of the study showed the effectiveness of using social networks in learning and forming positive attitudes towards knowledge society. [7]

3. Al-Otaibi study (2013) aimed to identify the effectiveness of social network Twitter on academic achievement and the development of cooperative learning skills of second year secondary student girls- computer syllabus. The study sample consisted of (60) and the results of the study showed the effectiveness of social networking Twitter on academic achievement and the development of cooperative learning skills. [8]

4. Seham (2012) conducted a study that aimed at detecting the effectiveness of social communication network on developing the technological concepts and Internet skills to students of prep nine at Gaza. The study sample consisted of (40) students, the results showed that learning through social networking is more effective and supports cooperative and collective activities. [9]

5. Warren Karincki (2010) conducted a study that aimed at detecting the impact of the use of Facebook site on the academic achievement of students, the study sample consisted of 219 students and its results showed that $79 \%$ of the respondents admitted that their addiction to Facebook site impacts negatively on their academic achievement. [10]

\section{The Study Population and its Sample}

The study population consisted of all teachers of social studies in Jahra educational zone whose number was (400) and the study sample was (150) teacher who was chosen randomly by $37 \%$ of the study population.

\section{The Study Tool}

To answer the study question, a questionnaire entitled (scale of difficulties in the use of Twitter in the educational process) was prepared and virtual credibility of the scale was assured by presenting it to a jury of specialists who gave their opinion in the questionnaire items, the stability of the scale was proven by re-application test to reach a reliability coefficient of (8.4), which is an acceptable ratio for the purposes of the study.

\section{The Study Procedures}

1. Preparing the study tool after reviewing and discussing in previous studies and theoretical literature

2. Making sure of the credibility and stability of the scale and making the final adjustments.

3. Getting the approvals required for the application of the scale then applying it.

4. Analyzing and discussing results.

5. Writing recommendations.

\section{Discussing the Results}

To answer the question of the study:- What are the difficulties of using (Twitter) in the educational process from the standpoint of social studies teachers in the State of Kuwait? Averages, iterations, percentages and standard deviations were calculated.

The following table represents the results 


\begin{tabular}{|c|c|c|c|c|c|}
\hline number & item & Average & $\begin{array}{l}\text { Standard } \\
\text { deviation }\end{array}$ & Percentage & Mark \\
\hline 1 & $\begin{array}{l}\text { The academic supervisor is unaware of the } \\
\text { educational role played by Twitter }\end{array}$ & 4.01 & 0.48 & 81.70 & very large \\
\hline 2 & No internet connection in most schools & 076 & 4.35 & 85.63 & very large \\
\hline 3 & $\begin{array}{l}\text { Lack of encouragement to use Twitter in social } \\
\text { studies }\end{array}$ & 1.8 & 3.69 & 74.23 & big \\
\hline 4 & Students are not qualified to use Twitter & 2.72 & 1.09 & 53.34 & little \\
\hline 5 & $\begin{array}{l}\text { Teachers suffer when following huge numbers } \\
\text { of ss on the internet }\end{array}$ & 3.41 & 0.95 & 68.40 & Medium \\
\hline 6 & The period time is not enough & 3.08 & 1.19 & 61.60 & Medium \\
\hline 7 & $\begin{array}{l}\text { Lack of experience of most teachers in using the } \\
\text { Twitter }\end{array}$ & 3.25 & 0.72 & 61.59 & Medium \\
\hline 8 & $\begin{array}{l}\text { Lack of incentives to teachers using Twitter } \\
\text { programs }\end{array}$ & 3.76 & 1.5 & 73.78 & big \\
\hline 9 & $\begin{array}{c}\text { parents are unaware of the role of Twitter in } \\
\text { education }\end{array}$ & 4.25 & 0.55 & 81.61 & Very big \\
\hline 10 & $\begin{array}{l}\text { School management is unaware of the role of } \\
\text { Twitter in education }\end{array}$ & 3.22 & 1.19 & 66.60 & Medium \\
\hline 11 & $\begin{array}{l}\text { Lack of training ourses to teachers using the } \\
\text { internet in teaching }\end{array}$ & 1.05 & 1.3 & 81.85 & Very big \\
\hline 12 & $\begin{array}{l}\text { Learners are unable to deal with Twitter } \\
\text { programs }\end{array}$ & 4.7 & 0.50 & 81.50 & Very big \\
\hline 13 & $\begin{array}{c}\text { Blogging on Twitter is limited to only } 140 \\
\text { character }\end{array}$ & 3.78 & 0.75 & 73.20 & big \\
\hline 14 & $\begin{array}{c}\text { Difficulty in developing performance skills on } \\
\text { Twitter program }\end{array}$ & 3.75 & 1.09 & 73.45 & big \\
\hline 15 & $\begin{array}{l}\text { Some teacher are not convinced with the } \\
\text { importance of using Twitter in education }\end{array}$ & 3.41 & 1.3 & 73.63 & big \\
\hline 16 & $\begin{array}{c}\text { Difficulty in applying depth discussions on } \\
\text { Twitter }\end{array}$ & 3.78 & 1.09 & 73.20 & big \\
\hline 17 & $\begin{array}{c}\text { Syllabuses do not include topics related to } \\
\text { Twitter }\end{array}$ & 4.35 & 0.76 & 85.63 & Very big \\
\hline
\end{tabular}

It appears from the previous table that the level of difficulties that face teachers in using social media communication (Twitter) in the educational process from their own point of view was very big on paragraphs $(1,2,9$, 11 , and 17) where the percentage of the response has reached $(81.70 \%, 85.63 \%, 81.61 \%, 81.85 \%, 81.50 \%$, and $63.85 \%)$ convectively. The reason behind that the degree of difficulty on paragraph (1) was great because most of the educational supervisors did not learn during their Bachelor's Degree studies the methods of tackling social media communications because this technology is relatively new. The reason why the degree of difficulty on paragraph (2) is very big was because of lack of wireless internet network at general secondary schools provided by the Ministry of Education in Kuwait. It was almost non-existent there at all in these schools. The main reason why there was greater difficulty in paragraph (9) was because there was lack of educational programs for guardians about the importance of the social media in the educational process. Most of the guardians see these social media as means of entertainment and wasting of time only. As for the reason why the degree of difficulty was great on paragraph (11) was because of the pattern and the traditional teacher training programs provided to teachers, and lack of awareness about the importance of the social media by training centers in the Ministry of Education of the importance of social media in the educational process and rareness of trainers and supervisors of training courses regarding the social media for educational purposes. As for the reason why there was great difficulty in paragraph (12), it was because of lack of awareness among teachers about the necessary skills for using the social media in the educational process and the poorness of the curriculum during the first stages of education in teaching the skills regarding the use of social media in the learning process. As for the great difficulty in paragraph (17), was because of lack of awareness of the officials responsible for curriculum planning and development of the importance of using the social media in the educational program.

As for paragraphs $(3,8,13,14,15$, and 16), these paragraphs were also great difficulty paragraphs and the percentages of difficulty reached $(74.23 \%, 73.78 \%, 73.20 \%$, $73.45 \%, 73 \%$, and $73.63 \%$ ) respectively. The main reason why the degree of difficulty was great was because the level of difficulty was so great in paragraph (3) was because of lack of awareness among of school administration about the importance of using social media in the educational process in addition to the differences in fields of specialization among schools' management officials and teachers of Social Studies. The reason for the great difficulty in paragraph (8) was because of lack of any articles in Teacher evaluation that states that teachers who use Social Media in the educational 
process are considered as competent teachers. The reason for the difficulty in paragraph (13) was because of limiting blogging in Twitter to 140 words, this adversely affects the evaluation of students' composition capabilities and their ability to express their ideas fully and clearly.

The reason why the level of difficulty was high in paragraph (14) was because Tweeter does not develop application skills and other simple or complicated skills that use hands and feet, this leads to lack of acquiring some necessary skills in school curriculum.

The reason why there was high level of difficulty in paragraph (15) was because some teachers think that the use of social media communication affects negatively the timetable of the school and hinders completing the curriculum on time, and that it needs more time to implement it, therefore to them it is a waste of time. And also lack of awareness among some teachers about the use of social media communication in the educational process is another reason.

The main reason for the difficulty in paragraph (16) was because of the limit of voice communication in twitter programs and lack of body language which affects negatively in any strategy for discussion in the educational process.

As for paragraphs $(5,6,7$ and 10), the levels of response were moderate, it came as follows: $(86.40 \%, 61.60 \%$, $61.59 \%$, and $66.60 \%$ ). The main reason was that the degree of difficulty in paragraph (5) was that the use of social media communication in the educational process will be an additional load on teachers during the working hours and afterwards. The reason for the modest difficulty in paragraph (6) is because of the high density of school curriculum and Para curriculum activities thereby leading to lack of time for regular classes. This leads to the fact that teachers of social studies in a continuous pressure of work load always trying to complete academic year curriculum on time.

The main reason why there is medium level of difficulty in paragraph (7) was because of lack of in-service vocational training programs for teachers on skills of using social media communication in the educational process.

The main reason for the medium difficulty in paragraph (10), was because of lack of training programs and awareness programs in school tools about the importance and ways of using social media communication in the educational process. Whereas, the ratio of response was little in paragraph (4), it was only (53.34\%).

Based on the above, we find that the study results has shown that there are many difficulties in using social media communication (Twitter) in the educational process from the perspective of social sciences teachers at this stage.

\section{Recommendations}

1. Holding more training courses for teachers in the field of using Twitter.

2. Introducing material and spiritual incentives to encourage teachers to use Twitter in education

3. Coordinating with the educational supervisor when using the networking programs of Twitter to ensure that teachers benefit completely from these programs

4. School management should continuously encourage teachers to use Twitter in teaching

5. Reorganizing the classroom to suit the use of modern technology and networking tools.

6. Providing the schools with broadband internet

7. Raising the parents' awareness concerning the importance of using social networking at schools and in the educational process.

8. School subjects should include activities that require the use of networking.

\section{REFERENCES}

[1] Maher Ismail Sabri, (2010). From teaching aids to educational technology. Riyadh: Al-Shaqri library.

[2] Fred Bin Ali Al-Ghamdi, Mohammed Moham med Salem, (2011).The impact of a strategy on the use of blogs education in the development of critical thinking skills and the survival of the impact of learning the legitimacy disciplines students in the Faculty of Education, University of Umm Al- Qura, of the Second International Conference on e-learning, education and research on, Riyadh.

[3] Jamal Al- Sharhan, (2003) Teaching aids and educational technology developments, Riyadh, King Fahd National Library.

[4] Abdel Hafez Salama,(2005)The impact of the Internet in academic achievement for students of Al-Quds -Open University- in Riyadh branch Computer decision in Education - Educational and Psychological Sciences Journal, 6 (1) . pp. 70-190.

[5] Blog of Abdul Karim al-Shammari (2012), The use of Twitter in Education (http://abdulkrem556.blogspot.com/2012/09/tw itter.htm)

[6] Nora Saud AL- Hazani,(2013): The effectiveness of social networks in the development of teaching and learning process to the students of the Faculty of Education at King Saud University, International Journal of Educational Research, the United Arab Emirates University number $33.2013 \mathrm{~m} \mathrm{p} \mathrm{r}$ (12-164)

[7] Jawaher Zahir Mohammad Anzi, (2013)The effectiveness of the use of social networks in the collection of science and the trend towards a knowledge society with the students average third grade in Medina., Ph.D. Introduction to the Curriculum and Instruction Department, College of Education, Umm Al Qura University, Saudi Saudi.

[8] Noura Bint -Saad bin Ahmed Al-Otaibi,( 2013) The effectiveness of social network Twitter to communicate (micro-blogging) on academic achievement and the development of cooperative learning skills of second grade students at secondary in the computer decision, the Third International Conference on e-Learning and Education Research remotely, held in Riyadh in.

[9] Seham Gamal El -Din Abou Atiya, - (2012) The effectiveness of social communication network wiki in technological 
concepts and skills development of the Internet ninth grade students basic Gaza, Faculty of Education - Department of Curriculum and Instruction.
[10] Aren, Karbiniski, (2010) Face book and the technology revolution, N,Y Spectrum publications. 